\title{
Avaliação de sistemas de produção de caprinos leiteiros na Região Sudeste do Brasil
}

\section{André Luigi Gonçalves ${ }^{1^{*}}$, Rogério de Paula Lana ${ }^{2,4}$, Ricardo Augusto Mendonça Vieira ${ }^{3}$, Douglas Sampaio Henrique ${ }^{1}$, Antonio Bento Mancio ${ }^{2}$, José Carlos Pereira ${ }^{2}$}

\footnotetext{
${ }_{1}$ Pós-graduação em Zootecnia - Departamento de Zootecnia - UFV.

2 Departamento de Zootecnia - UFV.

${ }^{3}$ LZNA/UENF - Campos dos Goytacazes.

${ }^{4}$ Bolsista $1 B$ do CNPq.

*In memoriam.
}

RESUMO - Um levantamento pormenorizado dos custos de produção de leite caprino foi realizado em três propriedades fornecedoras de uma mesma linha de leite na região Serrana Fluminense e na Zona da Mata mineira no ano de 2002: Capril Pedra Branca (CPB), Capril Vale da Braúna (CVB) e Capril Via Capri (CVC). As unidades Pedra Branca e Vale da Braúna representavam sistemas de produção em confinamento; o capril Via Capri adquiria toda a alimentação, enquanto o Vale da Braúna produzia parte do volumoso na própria propriedade. No Capril Via Capri, os animais permaneciam no pasto durante o dia, mas recebiam suplementação alimentar ao final da tarde. Os índices zootécnicos obtidos nessas propriedades foram comparados entre si e utilizados para identificar os componentes de maior influência sobre os custos finais da atividade. A alimentação dos rebanhos foi o item de maior impacto nos sistemas de produção e representou 60 a $70 \%$ do custo total. O sistema de produção do Capril Vale da Braúna foi o de melhor rentabilidade, pois, ao produzir sua fonte de volumoso, reduziu os custos com alimentação e forneceu os nutrientes necessários para manter a produção de seus animais.

Palavras-chave: cabra, custos, intensivo, leite, pasto

\section{Evaluation of systems of production of dairy goats in the region Southeast of Brazil}

\begin{abstract}
A survey was performed on milk production costs of three farms which supply milk for the same milk processing line, on the fluminense mountain region and Zona da Mata of Minas Gerais, in the year of 2002: Capril Pedra Branca (CPB), Capril Vale da Braúna (CVB) and Capril Via Capri (CVC). The Capril Pedra Branca and Capril Vale da Braúna represented confining production systems whereas Capril Pedra Branca bought all the feed while Capril Vale da Braúna produced part of the forage on the farm. In the Capril Via Capri animals were kept on pasture during the day, but received feed supplementation at evening. Technical indexes obtained of those farms were compared and used to identify which components caused more influence on the total costs of the production activity. Herd feeding was the most important item on the productive systems, varying between 60 and 70 percent of the total cost. The production system of Capril Vale da Braúna showed the best profitability because of their own forage production that decreased the costs with feeding, and supplied the nutrients necessary according to the production levels of the animals.
\end{abstract}

Key Words: costs, goat, intensive, milk, pasture

\section{Introdução}

No cenário agrícola mundial, é notória a evolução da caprinocultura leiteira. Em determinados países, os sistemas de criação, transformação e distribuição encontram-se em estágio avançado de desenvolvimento. Ao final da década de 80 , houve um crescimento significativo da produção mundial de leite de cabra, que atingiu 12.581.522 t em 2005 (FAO, 2007).
A maior produção de leite de cabra no continente americano é obtida no Brasil, cujo montante anual de leite produzido foi de 1,07\% (135.000 toneladas) do total mundial em 2005 (FAO, 2007). Apesar de ser o maior produtor do continente, as condições de criação e desempenho dos rebanhos brasileiros são díspares quanto aos estágios tecnológicos e gerenciais (Silva, 1998). Na Região Nordeste, a produção de leite de cabra é explorada de maneira semiintensiva, exceto nas propriedades rurais próximas aos 
grandes centros urbanos, geralmente localizadas na Zona da Mata, onde predomina o sistema de produção intensivo. No Sudeste, a produção é inteiramente intensiva, enquanto no Centro-Oeste e no Sul do país esse sistema é ainda incipiente (Silva, 1998).

As propriedades rurais da Zona da Mata de Minas Gerais, das regiões Serrana e Noroeste do Rio de Janeiro e das regiões Sul e Serrana do Espírito Santo têm sofrido reduções de tamanho consideráveis (IBGE, 2003). A redução do tamanho das propriedades rurais e a topografia característica destas regiões são fatores limitantes à produção de bovinos de corte ou de leite na escala necessária para torná-las um negócio rentável e atrativo aos produtores de toda esta macrorregião, uma vez que a política agrícola brasileira não estabelece a concessão de subsídios aos produtores rurais para cobrir os déficits financeiros gerados pelos sistemas de produção.

Existem vários fatores, dentro e fora da propriedade, que limitam o aumento da produtividade e da oferta de leite ou de carne caprina no Brasil: o potencial genético dos rebanhos, a sazonalidade da produção, a qualidade das forrageiras tropicais, o clima, o manejo, o intervalo de partos, a idade ao primeiro parto, o controle das enfermidades, o gerenciamento dos rebanhos, a nutrição e a alimentação dos rebanhos, entre outros.

A construção da sustentabilidade na caprinocultura leiteira depende da análise dos principais desafios e das possibilidades, que pode ser obtida por meio de estudos dos segmentos da cadeia produtiva. Por isso, é necessária a participação dos fatores de produção na composição dos custos de produção de leite em sistemas intensivos de produção de caprinos.

A desregulamentação e a globalização da economia brasileira na década de 90 e as novas exigências por qualidade forçaram os diferentes segmentos do sistema agroindustrial a aumentarem sua eficiência de produção (Krug, 2001), o que requer do produtor de leite elo mais frágil da cadeia, maior competitividade em produtividade, custo e qualidade. Assim, ocorreram grandes mudanças nos sistemas de produção, como a expansão de cultivos de áreas para pastagens, com altos níveis tecnológicos de produção e diferentes ganhos de produtividade e competitividade; a granelização da coleta de leite, que promove intensificação na utilização dos tanques de expansão; a valorização das terras próximas a grandes centros; os limites de financiamento para o crédito rural e a ausência de subsídios.

A análise econômica da atividade leiteira por meio de medidas de resultados técnicos e econômicos é forte subsídio para decisões quanto aos rumos do sistema de produção. Essa análise pode ser feita a partir de uma visão sistêmica (análise global da caprinocultura leiteira) ou com base nos diferentes setores do sistema de produção (análise setorizada dos centros de custos). Neste contexto, a análise econômica não é mais que uma análise zootécnica pautada em critérios de desempenho produtivo e financeiro da atividade, uma vez que, por definição, a zootecnia é uma ciência aplicada que envolve a adaptação econômica do animal ao ambiente criatório e vice-versa (Domingues, 1968).

Este trabalho foi realizado com o objetivo de fazer um levantamento pormenorizado dos custos de produção de leite em sistemas intensivos de caprinocultura leiteira, em condição de estabilidade, correlacionando-os aos índices zootécnicos obtidos para identificar os componentes de maior influência sobre os custos finais da atividade.

\section{Material e Métodos}

As avaliações técnicas e econômicas dos sistemas de produção de leite de cabra foram feitas por meio da comparação entre três criatórios no ano de 2002: Capril Pedra Branca (CPB), Capril Vale da Braúna (CVB) e Capril Via Capri (CVC). Essas propriedades faziam parte da linha de leite da CCA Laticínios, na área de atuação do Programa para o Desenvolvimento da Caprinocultura de Leite da Zona da Mata Mineira e Serrana Fluminense (PROCABRA-UFV), resultante de um convênio entre o laticínio e a Universidade Federal de Viçosa.

Os três sistemas foram escolhidos por apresentarem características semelhantes (Tabela 1), como a caracterização dos rebanhos, todos com animais da raça Saanen com padrão genético muito próximo e nível de produção similar. Todos utilizavam as mesmas tecnologias, como ordenha mecanizada, uso de tanque de expansão e equipamentos suficientes para a execução das tarefas rotineiras. Utilizou-se o programa PROCAPRI como ferramenta auxiliar ao gerenciamento do rebanho e registro sistemático de dados.

Os índices zootécnicos levantados foram: consumo alimentar e composição da dieta por categoria animal; produção de leite; período de lactação; intervalo de partos; taxas de fertilidade; prolificidade e mortalidade; percentual de fêmeas nascidas; peso ao nascimento; idade e peso à desmama; idade e peso à primeira cobrição; idade e peso ao primeiro parto; porcentagem de cabras lactantes pelo total de cabras; e porcentagem de cabras lactantes pelo total de animais no rebanho.

Os custos de produção foram estimados a partir das diretrizes apresentadas por Gomes (2000), após a tabulação dos dados em planilha eletrônica desenvolvida por esse autor para o acompanhamento de custos do Programa de Desenvolvimento da Produção de Leite (PDPL) elaborado 
Tabela 1 - Resumo de características dos sistemas avaliados

\begin{tabular}{lccc}
\hline Característica & \multicolumn{3}{c}{ Sistema } \\
\cline { 2 - 4 } & $\mathrm{CPB}^{1}$ & $\mathrm{CVB}^{2}$ & $\mathrm{CVC}^{3}$ \\
\hline Número de cabras em lactação & 127 & 60 & 129 \\
Número total de cabras & 150 & 65 & 150 \\
Número total de animais & 183 & 134 & 263 \\
Reprodutores & 5 & 3 & 3 \\
Cabritas desmamadas & 26 & 62 & 80 \\
Cabritas em aleitamento & - & 7 & 30 \\
\hline
\end{tabular}

${ }^{1}$ Capril Pedra Branca; ${ }^{2}$ Capril Vale da Braúna; ${ }^{3}$ Capril Via Capri.

pela UFV em convênio com a Nestlé, adaptado para as características caprinas. O critério adotado para a conversão do custo da atividade leiteira para o custo de produção do leite foi o da participação da renda deste produto na renda bruta da atividade (Gomes, 1999).

Os formulários para anotações dos dados foram entregues aos proprietários no início de cada mês referente ao período de janeiro a dezembro de 2002 e recolhido ao final, quando se faziam a avaliação técnica e a entrega dos formulários para o mês seguinte. A partir desses formulários, os valores foram lançados na planilha de custo, considerando a renda bruta e os lançamentos das despesas mensais, caracterizando os custos do mês e os percentuais de cada item. Em seguida, os valores foram acumulados, evidenciando o custo médio de 12 meses consecutivos de produção.

No cálculo da depreciação anual do capital imobilizado em benfeitorias, adotou-se o método de cotas constantes e, no cálculo da depreciação em equipamentos, utilizou-se o método de cotas variáveis preconizado por Antunes \& Engel (1999). A remuneração do capital investido foi calculada de acordo com as taxas de juros aplicadas pelos bancos oficiais ao setor de caprinocultura $(8,75 \%)$ na época da realização da pesquisa (2002).

\section{Resultados e Discussão}

O Capril Pedra Branca, situado no município de Bom Jardim (RJ), caracterizou-se como um sistema intensivo de produção de leite de cabra em condições de confinamento. As instalações eram compostas de um galpão com baias de piso em cama de maravalha, depósitos de volumoso e concentrado, sala de ordenha e de leite, sala de espera da ordenha, corredores de circulação, pista de alimentação, escritório e banheiros. Para concentrar todos os partos em março e abril e obter um pico de produção de leite em época de entressafra, o manejo de programa de luz nesta unidade era artificial. Todos os alimentos deste capril (Tabela 2) eram comprados. A ordenha era realizada duas vezes ao dia em sala com capacidade para 16 cabras, em sistema mecâ- nico do tipo balde ao pé, com quatro unidades e o resfriamento e armazenamento do leite eram realizados em tanque de expansão. A comercialização de animais (matrizes, reprodutores e animais de descarte) constituía uma fonte de renda para o capril.

O Capril Vale da Braúna, situado no município de Duas Barras (RJ), foi classificado como um sistema intensivo de produção de leite de cabra em condições de confinamento. O Capril era constituído de um galpão com baias de piso em cama de maravalha, depósitos para volumosos e concentrados, sala de ordenha e de leite, corredores de circulação, pista de alimentação, escritório e banheiro. Das fontes alimentares para o rebanho (Tabela 2), o concentrado e o feno eram comprados e a silagem produzida na propriedade. $\mathrm{O}$ aleitamento das crias era artificial, utilizando-se no primeiro dia de vida colostro de cabra tratado termicamente e, em seguida, sucedâneo lácteo (Tabela 2). A ordenha era realizada duas vezes ao dia, em sala com capacidade para oito cabras e sistema de ordenha mecânica tipo balde ao pé, com quatro unidades. O resfriamento e armazenamento do leite eram realizados em tanque de expansão.

O Capril Via Capri, situado no município de Belmiro Braga, MG, constituiu-se em um sistema misto de produção de leite de cabra em pastejo ao longo do dia, mas com suplementação volumosa. As instalações eram de madeira e estrutura metálica com o piso suspenso; a estocagem de concentrados, o local para processamento do capim e o tanque de expansão eram localizados em um galpão anexo. Das 8 às 17 h, os animais eram mantidos soltos em piquetes de Brachiaria decumbens e, ao final do dia, recebem suplemento de capim-napier acrescido de concentrado preparado no próprio capril. Na estação seca, com a escassez do capim, o produtor utilizava silagem de milho. O aleitamento das crias era artificial, com colostro de cabra tratado termicamente, seguido da administração de substituto lácteo (Tabela 2). A ordenha era realizada duas vezes ao dia em uma plataforma contígua ao galpão com capacidade para oito cabras. O sistema era de ordenha mecânica tipo balde ao pé, com quatro unidades. O resfriamento e armazenamento do leite foram realizados em tanque de expansão.

A área utilizada pelo Capril Pedra Branca para desenvolvimento da atividade correspondia a apenas 0,1 ha, de modo que o sistema de produção era totalmente intensivo (Tabela 3). Assim, o grau de especialização da atividade impunha a compra de toda a base alimentar (volumoso e concentrado). Apesar de a área utilizada para a produção no Capril Pedra Branca ser a menor entre os três sistemas, o custo de produção por unidade de área era o maior, em razão de sua localização, próxima à Nova Friburgo (12km até o centro), praticamente no perímetro urbano. 
Tabela 2 - Consumo e composição da dieta por categoria animal nos Capris

\begin{tabular}{|c|c|c|c|c|c|}
\hline \multirow[t]{2}{*}{ Categoria } & Volumoso (kg/dia) & Silagem (kg/dia) & Concentrado (kg/dia) & Sal mineral (kg/dia) & Subst. lácteo (L/dia) \\
\hline & \multicolumn{5}{|c|}{ Capril Pedra Branca (sistema intensivo) ${ }^{1}$} \\
\hline Cabritas em aleitamento & 0 & 0 & À vontade & 0 & 2,0 \\
\hline Cabras secas & À vontade & 0 & 0,400 & À vontade & 0 \\
\hline Cabras em lactação & 3,5 & 0 & $0,300 / \mathrm{L}$ & À vontade & 0 \\
\hline Reprodutor & À vontade & 0 & 0,200 & À vontade & 0 \\
\hline Cabritas em aleitamento & 0,150 & 0 & 0,075 & 0 & 1,2 \\
\hline Cabritas desmamadas & 0,060 & 0,600 & 0,400 & 0,02 & 0 \\
\hline Cabras secas & 0,150 & 1,500 & 0,600 & 0,03 & 0 \\
\hline Cabras em lactação & 0,250 & 2,400 & 1,500 & 0,03 & 0 \\
\hline \multirow[t]{2}{*}{ Reprodutor } & 0,150 & 2,500 & 0,400 & 0,04 & 0 \\
\hline & \multicolumn{5}{|c|}{ Capril Via Capri (sistema intensivo a pasto) ${ }^{3}$} \\
\hline Cabras em lactação & 2,500 & 2,000 & 1,000 & 0,03 & 0,0 \\
\hline Reprodutor & 2,000 & 1,500 & 0,300 & 0,03 & 0,0 \\
\hline
\end{tabular}

${ }^{1}$ Pré-secagem alfafa; ${ }^{2}$ Feno tifton; ${ }^{3}$ Napier.

Tabela 3 - Recursos disponíveis nos sistemas de produção de leite de cabra avaliados ${ }^{1}$

\begin{tabular}{|c|c|c|c|}
\hline \multirow[t]{2}{*}{ Item } & \multicolumn{3}{|c|}{ Sistema } \\
\hline & $\mathrm{CPB}^{2}$ & $\mathrm{CVB}^{3}$ & $\mathrm{CVC}^{4}$ \\
\hline Mão-de-obra permanente (pessoas) & 1 & 1 & 1 \\
\hline Custo do $\mathrm{m}^{2}$ de instalação ( $\mathrm{R} \$$ ) & 154,01 & 154,01 & 123,21 \\
\hline Área construída $\left(\mathrm{m}^{2}\right)$ & 920 & 730 & 270 \\
\hline Capital em animais (R\$) & $58.718,07$ & $42.995,74$ & $84.387,17$ \\
\hline Capital da terra efetiva usada na atividade ( $\mathrm{R} \$ / \mathrm{ha}$ ) & $38.503,65$ & $15.401,46$ & $7.700,73$ \\
\hline Capital circulante anual (R\$) & $151.447,69$ & $109.696,90$ & $110.807,09$ \\
\hline
\end{tabular}

1 Valores em Reais (R\$) corrigidos para maio de 2007 de acordo com IGP-DI da FGV; ${ }^{2}$ Capril Pedra Branca; ${ }^{3}$ Capril Vale da Braúna; ${ }^{4}$ Capril Via Capri.

O Capril Vale da Braúna, no entanto, dispunha de área maior para a atividade e produz iao volumoso, que constitui mais de $50 \%$ da base alimentar das cabras e minimiza as despesas pertinentes à aquisição de alimentos. $\mathrm{O}$ custo da área adicional onde era desenvolvida a atividade de plantio para obtenção da silagem em apenas em um terço do ano teve seu preço computado sobre o custo do produto, uma vez que nos outros dois terços do ano a área é utilizada em outras atividades não relacionadas à caprinocultura. Por se tratar de uma propriedade relativamente distante do perímetro urbano e com o acesso difícil no período das chuvas, o valor da terra era menor, o que reduzia consideravelmente os custos de produção.

Neste âmbito, a área do Capril Via Capri representou um custo menor por se tratar de uma região relativamente distante de grandes centros (aproximadamente $60 \mathrm{~km}$ de
Juiz de Fora, MG), porém, onde as propriedades não apresentavam outro atrativo além da produção primária. O custo por unidade de terra era menor, o que permitia destinar uma área maior, em comparação aos outros dois sistemas avaliados, à possível utilização como pasto para compor a alimentação dos animais. O custo das instalações desse sistema também refletiu um diferencial; enquanto nos outros dois sistemas as instalações tiveram custo de $\mathrm{R} \$ 154,00 / \mathrm{m}^{2}$ por apresentarem mesmo padrão de instalações, no Capril Via Capri, as instalações, por utilizarem madeira, apresentaram custo menor (R\$ $123,21 / \mathrm{m}^{2}$ ), mas não tão inferior, pois possuíam piso ripado, que implica maior desembolso inicial. Apesar do custo ligeiramente inferior das instalações do Capril Via Capri, a menor vida útil das mesmas pode se tornar uma desvantagem ao longo de sucessivos anos, o que justificaria o investimento mais alto feito nos outros dois 
sistemas em que são utilizadas baias com cama em vez de piso ripado. Outra vantagem em comparação ao piso ripado é o visível conforto que a cama oferece aos animais.

O sistema de ordenha, bem como o tanque de expansão utilizado em todos os sistemas, era idêntico. Desta forma, os custos com estes materiais foram os mesmos para cada sistema. A utilização dos mesmos equipamentos, no entanto, gera um questionamento: o número de cabras ordenhadas nos capris Pedra Branca e Via Capri era praticamente o dobro do Capril Vale da Braúna, logo, se os capris Pedra Branca e Via Capri apresentavam o dimensionamento adequado, o Capril Vale da Braúna estava superdimensionado, tanto quanto ao sistema de ordenha quanto à capacidade do tanque de expansão, em torno de $2.000 \mathrm{~L}$.

No Capril Via Capri, um funcionário cuidava de 263 animais, no Capril Pedra Branca de 183 e no Capril Vale da Braúna de 134, o que evidencia a subutilização da mão-deobra nos capris Pedra Branca e Vale da Braúna. O custo da mão-de-obra é diluído quanto maior o número de animais sob os cuidados de uma única pessoa, obviamente se não houver prejuízo aos tratos necessários. Além disso, o valor da mão-de-obra influencia o custo de produção, mas depende do mercado local, de modo que, quanto menor a disponibilidade, maior sua participação no custo do produto final.

O preço dos animais está sujeito às leis de mercado, pois a demanda e a oferta determinam os valores de compra e venda. Contudo, para os semoventes, não há como generalizar, pois o custo de um indivíduo pode variar de pouco a verdadeiras fortunas, dependendo do potencial genético, da origem, morfologia, produção e de diversos outros fatores. Neste estudo, foi considerado um preço médio de mercado, calculado com base nos sistemas estudados, em que uma fêmea no início da idade reprodutiva (seis a sete meses) custaria $\mathrm{R} \$ 320,86$ (valor corrigido pelo IGP-DI da FGV para maio de 2007). Assim, o capital investido em animais foi determinado multiplicando-se o número total de animais de cada sistema pelo valor médio de mercado calculado.

O capital circulante de cada sistema dependia de sua capacidade gestora, uma vez que este fator foi também considerado custo operacional efetivo, o que proporcionou diferencial baseado na condição em que se produz, em que a otimização do sistema implica menor dispêndio e, conseqüentemente, maior margem no processo.

Os índices zootécnicos de cada propriedade, quanto ao intervalo de partos (IEP), à idade à desmama (ID), à idade à primeira cobertura (IC), à idade ao primeiro parto (IP), ao período de serviço (PS) e ao período de lactação (PL) foram idênticos nos três sistemas (Tabela 4), portanto, os criadores já haviam assimilado esses aspectos relacionados às atividades de manejo tecnificado. A idade à desmama poderia ser mais precoce, o que promoveria redução nos custos com o sucedâneo lácteo, mas, conforme experiências baseadas em observações empíricas dos próprios criadores, a antecipação da desmama não permite aos animais atingir peso satisfatório para o acasalamento em idade mais precoce. Desse modo, quando a idade à primeira cobertura ocorre aos 7 meses de idade, obtém-se o primeiro parto aos 12 meses, quase sincronizando a estação reprodutiva. Além disso, mantém o IEP médio de 12 meses para todos os criatórios, até porque os animais que não parem neste intervalo são descartados por não atenderem a necessidade produtiva dos sistemas.

No sistema UNESP-Jaboticabal de distribuição dos partos ao longo do ano, aumenta-se consideravelmente o número de crias e a rotatividade do sistema. Desta forma, seria possível também intensificar o sistema de melhoramento por seleção, em virtude da maior disponibilidade de produtos. Conseqüentemente, haveria redução da lactação para sete meses, mais apropriada para os caprinos, pois reduz o período de serviço de sete para três meses. Outra possível vantagem seria a melhora da média produtiva do animal, uma vez que a curva de lactação seria interrompida no terço final, quando a produção geralmente é menor. Contudo, esta técnica ocasiona maior exposição dos animais ao estresse do parto, sendo recomendada principalmente para criatórios

Tabela 4 - Índices zootécnicos nos sistemas de produção de leite de cabra avaliados ${ }^{1}$

\begin{tabular}{|c|c|c|c|}
\hline \multirow[t]{2}{*}{ Item } & \multicolumn{3}{|c|}{ Sistema } \\
\hline & $\mathrm{CPB}^{1}$ & $\mathrm{CVB}^{2}$ & $\mathrm{CVC}^{3}$ \\
\hline Intervalo de partos (meses) & 12 & 12 & 12 \\
\hline Fertilidade (\%) & 86 & 82 & 80 \\
\hline Prolificidade (crias/parto) & 1,6 & 1,4 & 1,5 \\
\hline Fêmeas nascidas (\%) & 52 & 54 & 50 \\
\hline Peso ao nascimento (kg) & 3,4 & 3,2 & 3,0 \\
\hline Idade à desmama (dias) & 60 & 60 & 60 \\
\hline Peso à desmama (kg) & 13 & 13 & 11 \\
\hline Idade à primeira cobrição (meses) & 7 & 7 & 7 \\
\hline Peso à primeira cobrição (kg) & 35 & 35 & 32 \\
\hline Período de serviço (dias) & 215 & 215 & 215 \\
\hline Período de acasalamento (dias) & 45 & 60 & 60 \\
\hline Idade ao primeiro parto (meses) & 12 & 12 & 12 \\
\hline Peso ao primeiro parto (kg) & 52 & 49 & 46 \\
\hline Período de lactação (dias) & 305 & 305 & 305 \\
\hline $\begin{array}{l}\text { Produção de leite total } \\
\text { por animal (L/lactação) }\end{array}$ & 885 & 641 & 600 \\
\hline $\begin{array}{l}\text { Produção de leite total } \\
\text { no rebanho (L/ano) }\end{array}$ & 112.910 & 46.308 & 98.292 \\
\hline Mortalidade (\%) & 3,5 & 3,9 & 3,6 \\
\hline Cabras lactantes/total de cabras (\%) & 85 & 92 & 86 \\
\hline Cabras lactantes/animais totais (\%) & 69 & 45 & 49 \\
\hline
\end{tabular}

${ }^{1}$ Capril Pedra Branca; ${ }^{2}$ Capril Vale da Braúna; ${ }^{3}$ Capril Via Capri. 
não-estabilizados com o objetivo de atingir mais rapidamente o ponto de estabilidade, ou para o planejamento de melhor distribuição de partos ao longo do ano.

Foram observadas ligeiras diferenças em alguns índices, como fertilidade, 86, 82 e 80\% para o CPB, CVB e CVC, respectivamente (Tabela 4), o que indica possíveis falhas de manejo reprodutivo, tanto pela não manifestação de cios como pela falha em observá-los, uso incorreto de reprodutores ou ainda alguma deficiência nutricional.

Quando comparados o índice de fertilidade e a relação entre cabras em lactação e o número total de cabras, foram obtidos resultados diferentes. Na espécie caprina especializada em produção de leite, há dificuldade em encerrar a lactação, o que resulta em lactações mais extensas que as preconizadas para a espécie e até mesmo em animais que emendam lactações ou que produzem leite sem parir novamente por períodos muito mais extensos que os normais.

As diferenças na prolificidade e no percentual de fêmeas nascidas foram muito pequenas e, portanto, desconsideradas para efeito de comparação. No desenvolvimento ponderal, ou seja, no peso ao nascimento, à desmama, à primeira cobertura e ao primeiro parto, verificou-se similaridade entre os sistemas CPB e CVB. A diferença numérica do peso ao primeiro parto, que foi menor no $\mathrm{CVB}$, em virtude da dificuldade no atendimento às necessidades do animal nos cinco meses de gestação, resultou em peso menor. Havia um déficit de peso dos animais do CVC em comparação aos outros dois sistemas, conseqüentemente, as cabritas iniciavam a atividade reprodutiva com peso menor. Apesar de o AFRC (1993) recomendar que os animais sejam acasalados ao atingir 70\% do peso adulto de referência, no caso do CVC, o déficit nutricional causou redução na massa corporal dos animais adultos, o que talvez tenha limitado seu potencial produtivo.

O período de serviço nos criatórios apresentou diferença numérica entre o CPB e os outros dois sistemas e foi menor no CPB, o que resultou em maior concentração de partos e favoreceu o manejo de recém-nascidos. Um benefício direto foi o não-alongamento do período de amamentação dos filhotes, pois esta atividade demanda trabalho e gasto com mão-de-obra no preparo e na administração de colostro e sucedâneo lácteo.

O índice de mortalidade médio manteve-se na faixa aceitável nos três sistemas (menor que 5\%) e, quanto mais baixo, menor seu impacto no custo da atividade. Assim, o CPB e o CVC apresentaram índices menores que o CVB, o que constitui um diferencial na rentabilidade dos sistemas. A diferença nos dois primeiros criatórios evidencia resultado 3\% menor quanto a mortes no CPB em relação ao CVC, contudo, nestes sistemas, a mortalidade foi $10 \%$ menor que no CVB.

No sistema CPB, observou-se melhor resultado para produção total por animal, provavelmente um resultado da interação genótipo × ambiente (Tabela 5). Apesar da mesma origem, os animais do CVB apresentaram menor média, portanto, não basta a origem comum, uma vez que, dentro dos rebanhos, há uma distribuição normal, o que permite selecionar animais de segmentos diferentes do rebanho. A interação genótipo $\times$ ambiente afeta o desempenho dos animais dentro de cada sistema de produção, no entanto, não é possível definir qual fator, se genético, nutricional ou de manejo, exerce maior influência, pois, em todas as propriedades, tem-se como objetivo atender às demandas das funções produtivas. A média obtida no CVC foi similar à observada no CVB, o que mantém esses sistemas em condições semelhantes de resultado fenotípico.

A produção total do rebanho ao longo do ano (Tabela 5) possibilitou valores distintos para cada sistema e resultou da produção individual de cada animal e do número de animais em lactação. Maiores produções são observadas no CPB e CVC, com 112.910 e 98.292 L, respectivamente. A diferença pode ser atribuída à média lactacional dos animais, uma vez que o número de animais em lactação é basicamente o mesmo. O CVB apresentou menor volume, de 46.308 L no ano de 2002, com a metade dos animais em lactação dos outros dois sistemas.

Um dos pontos críticos nos sistemas é o percentual de cabras em lactação em relação ao rebanho total. A condição de estabilidade do CPB, com aproximadamente $70 \%$ do rebanho em lactação, manteve esse sistema em destaque sobre o CVB e o CVC, com apenas 45 e $49 \%$ de cabras em lactação em relação ao total de animais no rebanho. Esses sistemas encontram-se em expansão, de modo que animais jovens são mantidos para aumentar os rebanhos, o que requer a avaliação da manutenção do excedente como investimento - muitas vezes o produtor entende a criação

Tabela 5 - Produtividade média nos sistemas de produção de leite de cabra avaliados

\begin{tabular}{lccc}
\hline Item & \multicolumn{3}{c}{ Sistema } \\
\cline { 2 - 4 } & CPB $^{1}$ & CVB $^{2}$ & CVC $^{3}$ \\
\hline Produção (L/mês) & 11.291 & 3.859 & 8.191 \\
Média diária L/mês & 369 & 127 & 269 \\
Cabras em lactação & 127 & 60 & 129 \\
Litros por cabra/dia & 2,9 & 2,1 & 2,0 \\
Rebanho total & 183 & 134 & 263 \\
\% de cabras em lactação & 68,8 & 44,5 & 49,1
\end{tabular}

${ }^{1}$ Capril Pedra Branca; ${ }^{2}$ Capril Vale da Braúna; ${ }^{3}$ Capril Via Capri. 
de cabritas como integrante do custo de produção e superestima o custo do produto - e da viabilidade de expansão, pois, na verdade, ocorre retenção de animais como um todo e redução do descarte. O descarte é realizado visando ao progresso dos índices zootécnicos, no entanto, ao reter animais que deveriam ser descartados, o produtor mantém o sistema em condição de menor rentabilidade.

Os índices zootécnicos são ferramentas valiosas para o gerenciamento dos sistemas de produção, mas não conferem por si só competência para o processo decisório, uma vez que, equivocadamente, têm-se adotado tecnologias de última geração sem avaliação de seu impacto nos custos de produção, o que resulta em índices zootécnicos desconexos da realidade econômica.

Os custos de produção (Tabelas 6 e 7) foram estimados a partir das diretrizes apresentadas por Gomes (2000), após tabulação dos dados em planilha eletrônica (PCC - Leite) para análise dos componentes de custos das propriedades.

Os componentes de custos do Capril Pedra Branca (CPB) relacionados à alimentação (concentrado, volumoso, sal mineral e sucedâneo lácteo) representaram 74,76\% dos custos. O volumoso adquirido fora da propriedade representou $35,29 \%$ do custo total e $47,03 \%$ do total gasto com alimentação. O sucedâneo lácteo também teve custo significativo e representou $4,66 \%$ do custo total, o que é elevado se comparado à despesa com mão-de-obra, correspondente a 5,41\% do custo total da produção de leite. Também a aquisição integral do alimento volumoso, fornecido por terceiros, elevou o custo da produção, pois o produtor depende de oscilações de preço, principalmente relacionadas à disponibilidade do produto e à demanda, o que provoca preços exorbitantes durante os períodos de escassez de forragem. A compra programada no período de excedente de produção volumosa seria uma estratégia para contornar o problema, mas implicaria maior desembolso no período em que as cabras não se encontram em lactação, ou seja, em janeiro e fevereiro. Este período oferece vantagens para o produtor, em virtude da redução da mãode-obra, porém, resulta em dois meses de receitas praticamente nulas.

O sistema de produção do Capril Vale da Braúna (CVB), considerando os mesmos fatores de produção, foi semelhante ao do Capril Pedra Branca (CPB), contudo, o volumoso utilizado na propriedade, à base de silagem de milho balanceada com o concentrado em uma dieta visando ao atendimento das exigências nutricionais dos animais, refletiu de forma marcante sobre a produção. Neste sistema de produção especificamente, a alimentação, mesmo com a redução considerável de seu impacto sobre os custos totais, em comparação ao CPB, foi o item de maior influência sobre os
Tabela 6 - Resumo das rendas e dos custos $^{1}$ da atividade leiteira nos sistemas de produção de leite de cabra avaliados

\begin{tabular}{lrrr}
\hline Especificação & \multicolumn{3}{c}{ Sistema de produção } \\
\cline { 2 - 4 } & \multicolumn{1}{c}{$\mathrm{CPB}^{2}$} & \multicolumn{1}{c}{$\mathrm{CVB}^{3}$} & \multicolumn{1}{c}{$\mathrm{CVC}^{4}$} \\
\hline Renda bruta - RB & & & \\
Leite & $141.674,95$ & $102.592,21$ & $97.706,86$ \\
Animais & $29.845,98$ & $25.858,28$ & $25.027,37$ \\
Total RB & $171.520,93$ & $128.450,49$ & $122.734,23$ \\
Custo de produção & & & \\
\hline
\end{tabular}

Custo operacional efetivo - $\mathrm{COE}$

\begin{tabular}{lrrr}
$\begin{array}{l}\text { Mão-de-obra } \\
\text { contratada } \\
\text { (manejo do rebanho) }\end{array}$ & $9.186,91$ & $9.186,91$ & $9.186,91$ \\
Forrageiras & & & \\
Concentrados & $59.948,76$ & $12.693,68$ & $9.728,59$ \\
Leite para cabritas & $56.632,39$ & $49.457,42$ & $5.937,94$ \\
Sal mineral & $7.918,49$ & $7.237,06$ & $46.890,51$ \\
Medicamentos & $2.500,58$ & $1.988,16$ & $6.914,70$ \\
Material de ordenha & $2.718,02$ & $2.373,10$ & $2.292,79$ \\
Energia e combustível & $3.007,94$ & $2.415,73$ & $2.083,59$ \\
Inseminação artificial & $2.355,61$ & $2.693,70$ & $2.418,30$ \\
Impostos e taxas & 471,12 & 598,54 & $2.545,95$ \\
Reparos de benfeitorias & $2.849,40$ & $4.552,95$ & 0,00 \\
Reparos de máquinas & $1.522,09$ & $1.411,07$ & $4.458,63$ \\
Outros gastos de custeio & $1.105,32$ & 908,58 & 890,70 \\
Total COE & $15.7061,51$ & $97.836,43$ & $97.901,57$ \\
\hline
\end{tabular}

Custo operacional total - COT

Custo operacional $\quad 15.7061,51 \quad 97.836,43 \quad 97.901,57$ efetivo

Depreciação

\begin{tabular}{lrrr} 
Benfeitorias & $2.447,34$ & $1.772,21$ & $1.772,21$ \\
Máquinas & $3.041,17$ & $2.202,23$ & $2.202,23$ \\
Total COT & $162.550,02$ & $101.810,86$ & $101.876,01$ \\
$\begin{array}{l}\text { Custo total - CT } \\
\text { Custo operacional } \\
\text { total }\end{array}$ & $162.550,02$ & $101.810,86$ & $101.876,01$ \\
\hline
\end{tabular}

total

\begin{tabular}{lrrr}
\hline Remuneração de capital & & & \\
Benfeitorias & $2.825,23$ & $2.045,87$ & $2.045,87$ \\
Máquinas & 917,75 & 664,57 & 664,57 \\
Animais & $3.563,04$ & $2.580,13$ & $2.580,13$ \\
Forrageiras não anuais & 0,00 & 0,00 & 654,95 \\
Total CT & $169.856,04$ & $107.101,43$ & $107.821,53$ \\
\hline
\end{tabular}

Indicadores de resultados

\begin{tabular}{lrrr}
$\begin{array}{l}\text { Margem bruta total } \\
\text { (RB - COE) - R\$/ano }\end{array}$ & $14.459,42$ & $30.614,06$ & $24.832,66$ \\
$\begin{array}{l}\text { Margem líquida total } \\
\text { (RB-COT) - R\$/ano }\end{array}$ & $8.970,90$ & $26.639,62$ & $20.858,22$ \\
$\begin{array}{l}\text { Lucro total } \\
\text { (RB-CT) - R \$/ano }\end{array}$ & $1.664,88$ & $21.349,05$ & $14.912,71$ \\
$\begin{array}{l}\text { Margem bruta/ } \\
\text { área - R } \$ \text { /ha }\end{array}$ & $14.4594,19$ & $30.614,06$ & $24.832,66$ \\
$\begin{array}{l}\text { Taxa de retorno do capital } \\
\text { sem terra - \% ao ano }\end{array}$ & 6,71 & 21,33 & 21,81 \\
$\begin{array}{l}\text { Taxa de retorno do capital } \\
\text { com terra - \% ao ano }\end{array}$ & 4,60 & 19,99 & 16,16 \\
\hline
\end{tabular}

1 Valores em reais (R\$) e corrigidos para maio de 2007 de acordo com IGP-DI da FGV ${ }^{2}$ CPB - Capril Pedra Branca ${ }^{3}$ CVB - Capril Vale da Braúna; ${ }^{4}$ CVC - Capril Via Capri; ${ }^{5}$ Cada sistema de produção fornecia forrageiras diferentes para os rebanhos: CPB - feno e pré-secado; CVB - silagem e feno; CVC - pastagens e capineiras. 
Tabela 7 - Rendas e custos $^{1}$ relativos ao total de leite produzido nos sistemas de produção de leite de cabra avaliados

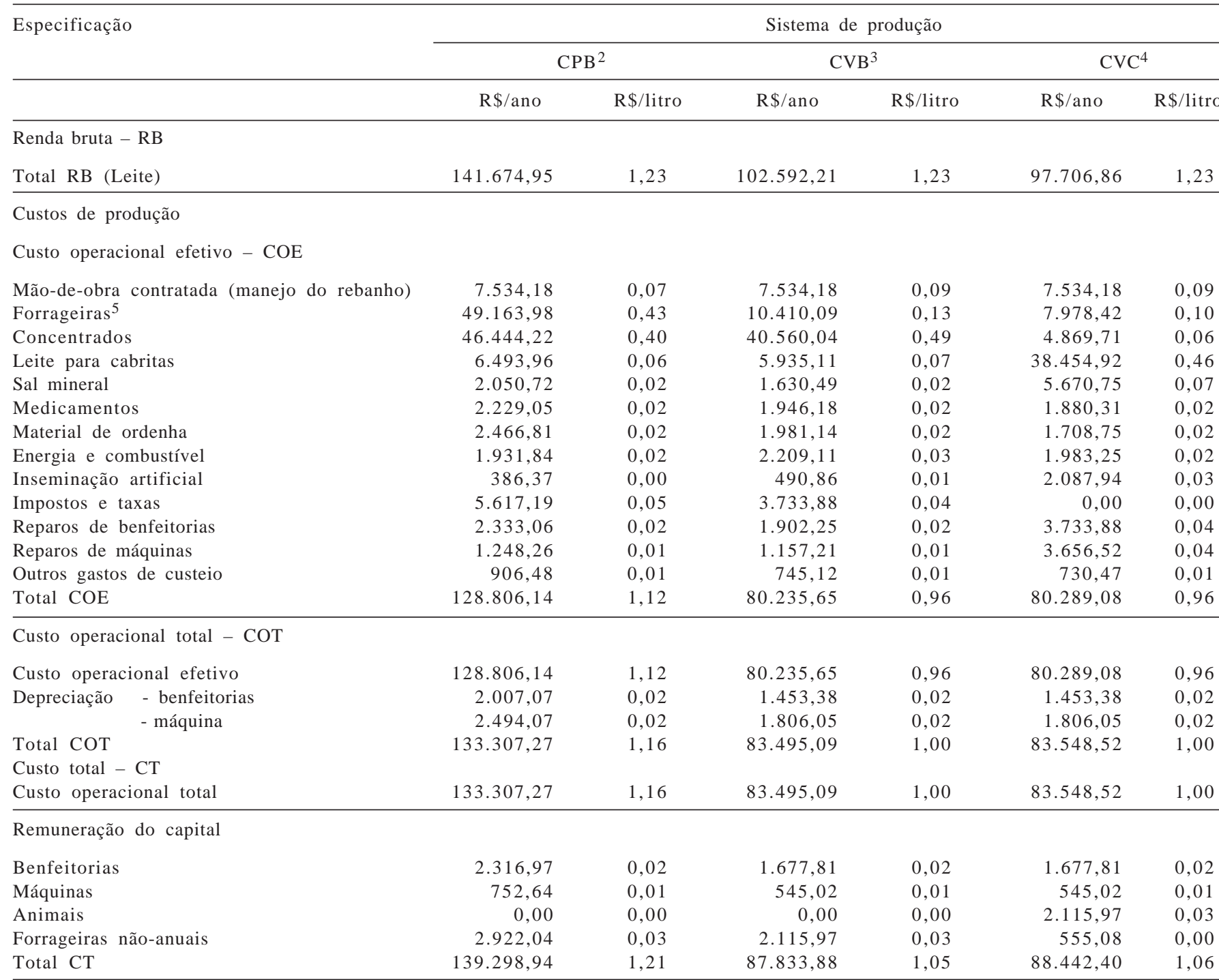

Indicadores de resultados

\begin{tabular}{llll} 
Margem bruta unitária (RB - COE) - R\$/litro & 0,13 & 0,27 & 0,27 \\
Margem líquida unitária (RB - COT) - R\$/litro & 0,08 & 0,23 & 0,23 \\
Lucro unitário (RB - CT) - R\$/litro & 0,02 & 0,18 & 0,17 \\
\hline
\end{tabular}

${ }^{1}$ Valores em Reais (R\$) e corrigidos para maio de 2007 de acordo com IGP-DI da FGV; ${ }^{2}$ CPB - Capril Pedra Branca; ${ }^{3}$ CVB - Capril Vale da Braúna; ${ }^{4}$ CVC - Capril Via Capri; 5 Cada sistema de produção fornecia forrageiras diferentes para os rebanhos: CPB - feno e pré-secado, CVB - silagem e feno, CVC - pastagens e capineiras.

custos. Os custos referentes aos impostos (4,03\%) também representaram parcela significativa dos custos efetivos. A impossibilidade de interferência neste fator consistiu em mais um dos complicadores na viabilização do sistema de produção em questão.

O sistema semi-intensivo do Capril Via Capri (CVC), baseado em pastagem de capim Brachiaria decumbens, foi considerado de forma análoga. Havia uma tentativa de se efetuar rotação de pastos na área, dividida em quatro piquetes, para que o pasto atendesse parte das necessidades em fibra alimentar. O complemento oferecido, à base de capim-napier picado ou silagem de milho no período da seca, era acrescido de concentrado comercial na tentativa de atender às exigências nutricionais.

No intuito de comparar cada componente do custo de produção em relação à sua participação percentual em cada um dos sistemas avaliados, foram mantidos na simulação o mesmo número de animais e os mesmos índices zootécnicos obtidos em cada sistema no período de análise (Tabela 8).

A participação na composição do custo oscilou de acordo com o sistema de produção, isto é, o custo de determinado item, como a mão-de-obra, representou maior impacto nos sistemas CVB e CVC, uma vez que, no CPB, os custos referentes a volumoso representaram maior propor- 
ção no custo total. O uso dos fatores de produção e os demais recursos disponíveis que agregam custos à produção resultaram de ações administrativas que nem sempre são percebidas ou consideradas pelo produtor. Nas análises dos capris, alguns problemas se destacaram: as matrizes que deveriam ter sido descartadas eram mantidas no rebanho; os rebanhos eram ainda jovens, resultantes da retenção de todas as fêmeas nascidas, seja pela falta de liquidez ou pela necessidade de ampliação do rebanho, neste caso, os produtores não consideraram o custo de produção destas fêmeas como investimento; o menor descarte resultava na manutenção de animais menos produtivos, o que implica maior custo com alimentação (igual para as categorias mais produtivas).

No sistema de confinamento, no qual se utilizava exclusivamente o pré-secado como forragem, o volumoso participou dos custos mais que concentrado e representou, somente no item alimentação, 74,76\% do custo total do leite, enquanto a mão-de-obra foi o segundo fator de importância (5,41\% do custo). Outro fator de relevância foi o sucedâneo lácteo, uma vez que, além do custo muito menor que do leite de cabra, possibilita o controle da transmissão de artrite encefalite viral dos caprinos (CAEV), o fornecimento de um produto mais regular que a aquisição de leite de vaca e permite o estoque do volume necessário para toda a estação de nascimento.

A participação de impostos e taxas, que contribuem com 4,03\% do custo total, também foi fator de grande impacto no sistema de produção. No modelo de confinamento, a utilização de silagem como fonte volumosa foi um diferencial na composição dos custos, pois o volumoso representou apenas $11,85 \%$ do custo total. Computada a alimentação total, sua participação nos custos foi de $66,65 \%$, ou seja, $8 \%$ menor que no modelo em que o pré-secado foi utilizado como volumoso exclusivo. A utilização de alimentos mais “nobres” justifica-se para o atendimento de demandas de animais com potencial produtivo maior, o que não foi caracterizado neste caso, em que a média de produção do CPB foi de $2,9 \mathrm{~kg} / \mathrm{animal} / \mathrm{dia}$ e poderia ser plenamente atendida com alimentos de menor custo, como a silagem de milho.

Tabela 8 - Valores percentuais dos custos de produção nos sistemas de produção de leite de cabra avaliados

\begin{tabular}{|c|c|c|c|}
\hline Item & $\mathrm{CPB}^{1}$ & $\mathrm{CVB}^{2}$ & $\mathrm{CVC}^{3}$ \\
\hline Custo de produção & confinamento & confinamento & pastejo \\
\hline \multicolumn{4}{|l|}{ Custo operacional efetivo - COE } \\
\hline Mão-de-obra contratada para manejo do rebanho & 5,41 & 8,58 & 8,57 \\
\hline Manutenção de pastagens & 0,00 & 0,00 & 9,08 \\
\hline Compra de feno ou pré-secado & 35,29 & 0,00 & 0,00 \\
\hline Silagem & 0,00 & 11,85 & 5,54 \\
\hline Concentrados & 33,34 & 46,18 & 43,75 \\
\hline Leite para cabrita & 4,66 & 6,76 & 6,45 \\
\hline Sal mineral & 1,47 & 1,86 & 2,14 \\
\hline Medicamentos & 1,60 & 2,22 & 1,94 \\
\hline Material de ordenha & 1,77 & 2,26 & 2,26 \\
\hline Energia e combustível & 1,39 & 2,52 & 2,38 \\
\hline Inseminação artificial & 0,28 & 0,56 & 0,00 \\
\hline Impostos e taxas & 4,03 & 4,25 & 4,25 \\
\hline Reparos de benfeitorias e de máquinas & 1,67 & 2,17 & 2,79 \\
\hline Outros gastos de custeio & 1,55 & 2,17 & 2,20 \\
\hline Total COE & 92,47 & 91,35 & 91,35 \\
\hline \multicolumn{4}{|l|}{ Custo operacional total - COT } \\
\hline $\begin{array}{l}\text { Custo operacional efetivo } \\
\text { Depreciação: }\end{array}$ & 92,47 & 91,35 & 91,35 \\
\hline Benfeitorias & 1,44 & 1,65 & 1,65 \\
\hline Máquinas & 1,79 & 2,06 & 2,05 \\
\hline Total COT & 95,70 & 95,06 & 95,06 \\
\hline \multicolumn{4}{|l|}{ Custo total - CT } \\
\hline Custo operacional total & 95,70 & 95,06 & 95,06 \\
\hline \multicolumn{4}{|l|}{ Remuneração do capital em } \\
\hline Benfeitorias & 1,66 & 1,91 & 1,91 \\
\hline Máquinas & 0,54 & 0,62 & 0,62 \\
\hline Animais & 2,10 & 2,41 & 2,41 \\
\hline Forrageiras não anuais & 0,00 & 0,00 & 0,45 \\
\hline Total CT & 100,00 & 100,00 & 100,00 \\
\hline
\end{tabular}

${ }^{1}$ Capril Pedra Branca; ${ }^{2}$ Capril Vale da Braúna; ${ }^{3}$ Capril Via Capri. 
A partir dos dados obtidos no sistema de produção do CPB por meio de simulação, considerando a melhor produtividade dos animais, haveria decréscimo considerável no custo de produção em função da escala, o que reduziria o prejuízo com a utilização desse volumoso. Aumentando a produtividade de 2,9 para 3,0 ou 3,5 L, ocorreria decréscimo no custo de produção, que passaria de $\mathrm{R} \$ 1,21$ para $\mathrm{R} \$ 1,17$ e R \$ 1,05/L de leite, respectivamente (valores corrigidos pelo IGP-DI da FGV para maio de 2007).

No caso do CVB, a mão-de-obra teve maior participação nos custos $(8,58 \%)$, enquanto os fatores relacionados à alimentação tiveram redução. Os outros custos tiveram o mesmo efeito que o da mão-de-obra, o que refletiu em maior proporção para os custos relacionados aos impostos e às taxas, que representaram $4,25 \%$ do custo de produção. Semelhantemente, o modelo semi-intensivo, no qual o pasto constituiu fonte parcial de alimentação volumosa, teve o mesmo custo do modelo de confinamento com silagem. Os investimentos em maior área disponibilizada para os animais (de 0,1 para 5,0 ha) deveriam justificar sua melhor utilização, uma vez que os custos inerentes a toda a estrutura para pastejo (terra, cercas e outros) seriam aumentados e, ainda assim, seria necessária suplementação volumosa e concentrada a fim de atender à demanda nutricional desses animais com o objetivo de manter os mesmos níveis de produção semelhantes aos outros dois casos.

Outro fator relacionado ao sistema de pastejo é o aspecto etológico do animal. O período de maior disponibilidade de pastagens na Região Sudeste, o verão, é também a estação chuvosa e, nessas condições climáticas, as cabras leiteiras deixam de ir ao pasto, o que implica a necessidade de se efetuar alguma estratégia de suplementação ao pasto. No inverno (seca), a necessidade de suplementação é mantida pela escassez de nutrientes no pasto, que, no caso, era formado por Brachiaria decumbens.

Neste contexto, questiona-se a prioridade no sistema de produção: se atender às exigências dos animais visando produtividade em busca de viabilidade econômica no sistema ou se utilizar animais de menor potencial em um sistema menos eficiente tecnicamente. Deve-se considerar o preço de oportunidade, pois existe a necessidade de maior número de animais para produzir o mesmo volume de leite.

Do ponto de vista zootécnico, maior número de animais aumenta a demanda global de nutrientes para mantença. $\mathrm{O}$ pasto poderia ser usado para atendê-la, contudo, o volume de produção, fator importantíssimo na caprinocultura para justificar a manutenção de linhas de leite regulares, não pode deixar de ser considerado. Essa condição impõe a necessidade de maior área para o sistema e, dependendo da região, inviabiliza sua implantação. Sistemas estruturados dessa forma deveriam apresentar ligeiro aumento no item alimentação, o que totalizaria aproximadamente $70 \%$ do custo total em comparação ao confinamento que utiliza silagem de milho como fonte volumosa (Tabela 8). Contudo, o custo é inferior ao do pré-secado. Os demais valores foram semelhantes aos observados no confinamento com silagem como volumoso.

Quando considerada a depreciação das benfeitorias na composição dos custos, observou-se aumento do CPB para o CVB, que foi equivalente ao do CVC, o que está relacionado à redução no custo da alimentação, o que favoreceu a participação dos outros itens na composição dos custos dos outros sistemas. Contudo, a redução na área disponível do galpão no CVC utilizando material menos resistente, como madeira, os valores atribuídos à depreciação foram maiores. Este aumento é crescente quando se considera a depreciação das máquinas, pois há maior utilização desses bens.

No custo total, houve pequena rentabilidade no sistema de produção do Capril Pedra Branca, com ganho de aproximadamente R \$ 0,03 por litro de leite. Os outros modelos apresentaram rentabilidade de aproximadamente $\mathrm{R} \$ 0,18$ por unidade produzida (sete vezes maior), apesar dos menores índices zootécnicos em relação ao Capril Pedra Branca. A possibilidade de produção de volumoso na propriedade pode ser uma alternativa de grande impacto sobre os custos. No entanto, no processo decisório, deve-se considerar se a área permite produção de silagem ou se a região possibilita a compra deste produto.

Outro aspecto é a taxa de retorno do capital, que, no sistema de produção CPB sofre redução de 31,49\% quando incluído o valor investido na terra, principalmente pelo fato de a unidade de terra neste capril ser extremamente valorizada. No caso do CVB, a avaliação da taxa de retorno com a terra sofre redução de apenas 6,31\% ao ano. Quando a atividade depende de áreas para pastejo, a rentabilidade cai de 16,99 para 12,59\% ao ano para o CVC, uma redução de $25,90 \%$, apesar de esta propriedade apresentar o menor valor de unidade de área, o que permite redução significativa da rentabilidade com a maior participação da terra no sistema de produção. O retorno observado para o CVB, cujas taxas foram de 16,62 e 15,57\% com e sem terra, respectivamente, foi três vezes maior que o observado no sistema do CPB, similar ao CVC sem considerar a terra e $19,16 \%$ maior considerando a terra.

A escala de produção pode ser utilizada para melhorar a rentabilidade dos sistemas intensivos de produção, uma vez que, quanto maior, mais elevada é a diluição dos custos fixos. Entretanto, a busca de diluição de custos em sistema intensivo que tenha como meta a estabilização da condição 
do animal para produzir dificulta a adoção de medidas restritivas em determinadas situações que sinalizem um ótimo econômico diferente de um ótimo zootécnico. Pode-se inferir que este sistema gera escala e volume de recursos que permitem produção empresarial, mas com custo de produção alto. Não obstante, na comercialização dos animais excedentes, estes valores seriam computados na rentabilidade final da atividade leiteira. Contudo, em razão da baixa liquidez de caprinos leiteiros especializados, esta abordagem é necessária em outros estudos.

\section{Conclusões}

O sistema de produção do Capril Vale da Braúna é o que apresenta melhor rentabilidade, pois a produção de fonte de volumoso reduz os custos com alimentação e possibilita o fornecimento dos nutrientes necessários à produção dos animais. A alimentação dos rebanhos é importante no estabelecimento da rentabilidade, pois é item de maior impacto nos sistemas de produção (60 a 70\%). Pesquisas visando à otimização de rações totais para cabras leiteiras devem ser feitas, principalmente visando à escolha de ingredientes que, combinados, possibilitem maior rentabilidade para o capital investido. As propriedades avaliadas possuem características peculiares que influenciaram os resultados da avaliação. Estudos mais abrangentes sobre os aspectos zootécnicos e econômicos da caprinocultura leiteira são necessários para obtenção de melhores referências para outros sistemas de produção.

\section{Literatura Citada}

AGRICULTURAL AND FOOD RESEARCH COUNCIL - AFRC. Energy and protein requirements of ruminants. Wallingford: CAB International, 1993. 159p.

ANTUNES, L.M.; ENGEL, A. Manual de administração rural custo de produção. 3.ed. Guaíba: Agropecuária, 1999. 196p.

DOMINGUES, O. Introdução à Zootecnia. 3.ed. Rio de Janeiro: Edições SAI, 1968. 392p. (Série Didática, 5).

FOOD AND AGRICULTURE ORGANIZATION - FAO [2007]. FAOSTAT - FAO Statistics Division/ProdSTAT: livestock (primary and processed). Disponível em: <http://faostat.fao.org/ site/596/DesktopDefault.aspx?PageID=569> Acesso em: 25/6/2007

GOMES, S.T. Cuidados no cálculo do custo de produção de leite. In: SEMINÁRIO SOBRE METODOLOGIAS DE CÁLCULO DO CUSTO DE PRODUÇÃO DE LEITE, 1., 1999, Piracicaba. Anais... Piracicaba: Universidade de São Paulo, 1999. (CD-ROM).

GOMES, S.T. Mão-de-obra contratada versus familiar na produção de leite. In: GOMES, S.T. (Ed.) Economia da produção de leite. Belo Horizonte: Itambé, 2000. p.16-18.

INSTITUTO BRASILEIRO DE GEOGRAFIA E ESTATÍSTICA IBGE. Tabela 2001: efetivos dos rebanhos. Disponível em $<$ http://www.ibge.gov.br>. Acesso em: 10/7/2003.

KRUG, E.E.B. Sistemas de produção de leite: identificação de "benchmarking”. Porto Alegre: Pallotti, 2001. 256p.

SILVA, R.R. Agribusiness da caprinocultura de leite no Brasil. Salvador: Bureau, 1998. 74p. 